\title{
Isolation and Characterization of Two Cucurbitane Type Triterpenoid Glycocide from 1-Butanol Soluble Part of Momordica charantia Fruit Pulp Juice
}

\author{
MShakhawoat Hossain ${ }^{1}$, M Kamrul Hasan ${ }^{2 *}$, M Shoeb ${ }^{2}$, M I R Mamun ${ }^{2}$, N Nahar ${ }^{2}$ and M Mosihuzzaman ${ }^{2}$ \\ ${ }^{1}$ Department of Arts and Sciences, AUST, 141-142, Love Road, Tejgaon Industrial Area, Dhaka-1208, Bangladesh \\ ${ }^{2}$ Department of Chemistry, Dhaka University, Dhaka-1000, Bangladesh
}

(Received: 30 April 2018; Accepted: 9 July 2018)

\begin{abstract}
Momordica charantia is a member of the Cucurbitaceae family having diverse biological activities. Two cucurbitane type triterpene glycoside have been isolated from 1-butanol soluble part of clear juice of $M$. charantia fruit pulp through column chromatography and HPLC. The isolated compounds were characterized as compound MC1 (3 $\beta, 7-O-\beta$-glucopyranosyl-25methoxy cucurbita -5-en-19-al) and compound MC2 (5ß, 19-epoxy- 3- O-glucopyranosyl-25 methoxy cucurbita-6, 23-dien) with the help of UV Spectroscopy, Thin Layer Chromatography, IR Spectroscopy, ${ }^{1} \mathrm{H},{ }^{13} \mathrm{C}$ and dept-135 NMR. The proposed structures of the compounds were further confirmed by comparing the ${ }^{13} \mathrm{C}-\mathrm{NMR}$ values of the compounds with previous reported data.
\end{abstract}

Keywords: Momordica charantia, Fruit pulp juice, 1-butanol soluble part, Cucurbitane glycoside.

\section{Introduction}

Momordica charantia or bitter Melon, also known as bitter gourd, African cucumber, karela, grows in tropical areas, including parts of East Africa, Asia, the Caribbean, Middle East, Central and South America ${ }^{1-2}$, where it is used as a vegetable as well as a medicine. Although fruit is the safest and most useful part of the plant, the seeds, leaves, and vines of bitter melon have all been used. In the literature several bioactive compounds of $M$. charantia fruit have been reported $^{3,7}$; they are classified as proteins, lipids, carbohydrates, triterpenoids, saponins, polypeptides, flavonoids, sterols and others.

It is proved that polysaccharides from $M$. charantia fruits possess antidiabetic, antitumor, immune enhancing, antioxidant, neuroprotective and antimicrobial activities ${ }^{3-9}$. Proteins and peptides isolated from M. charantia are $\alpha$ momorcharin $(\alpha-\mathrm{MMC}), \quad \beta$-momorcharin $(\beta$-MMC), $\gamma$ momorcharin, ribosome inactivating proteins (RIPs), Momordica anti-HIV protein of $30 \mathrm{kD}$ (MAP30), which possess RNA N-glycosidase activity, phospholipase activity, anti-tumour, anticancer and anti-microbial activity ${ }^{7,8,10-12}$. Saponins are a class of glycosides, found in the roots, stems, leaves and fruit of the M. charantia $^{13}$. The major chemical constituents of saponins are tetracyclic triterpenoids and their glycosides, which are known as cucurbitanes. Many pharmacological investigations indicated that cucurbitanes from $M$. charantia shows both anti-diabetic and hypoglycaemic activities ${ }^{14}$. Cucurbitanetype compounds, isolated from the methanolic extract of $M$. charantia fruits, such as momordicosides A, C, F1, I and K; goyasaponins I, II, and III and goyaglycosides a, b, c, d, e, $\mathrm{f}, \mathrm{g}$ and $\mathrm{h}$ are very well known ${ }^{13} . \beta, 19$-epoxy-3 $\beta, 25-$ dihydroxycucurbita-6, 23 (E)-diene and $3 \beta, 7 \beta, \quad 25$ trihydroxycucurbita- 5, 23 (E)-dien-19-al are two cucurbitane type triterpenoids isolated from the methanol extract of $M$. charantia, lowered the blood sugar in diabetic mice ${ }^{15}$. Eight new cucurbitane-type glycosides, kugua saponins A-H were isolated by Zhang et al. from the directed fractionation of $M$. charantia fruits ${ }^{16}$. Zhang et al. also isolated four new cucurbitane-type triterpenes and a

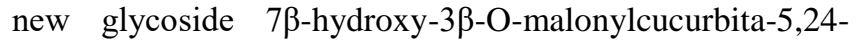
diene-19-a-23-O- $\beta$-D-glucopyranoside from the rattans of wild $M$. charantia ${ }^{17}$.

Besides bioactive compounds, unsaturated fatty acids, amino acids, minerals, vitamins are also contained in $M$. charantia $^{18-19}$. Gallic acid, gentistic acid, t-ferulic acid, $\mathrm{p}$ coumaric acid, o-coumaric acid, (+)-catechin, (-)epicatchin and vanillic acid are important flavonoids and phenolic compounds isolated from $M$. charantia ${ }^{20-21}$. In the literature research on different extract of $M$. charantia fruit is reported, but almost no evidence of work with 1-butanol extract. In continuation of our search for bioactive compounds we have selected the 1-butanol extract of $M$. charantia fruit pulp juice for biological and chemical analysis.

\section{Materials and Methods}

\section{General Methods}

Analytical or laboratory grade solvents and chemicals used in the research were collected from E. Merck (Germany), BDH (England) and RDH (Sweden). Commercial grade methanol, ethanol, chloroform and DCM were distilled in a glass distillation apparatus before use. All evaporations were carried out under reduced pressure using rotary vacuum evaporator at bath temperature not exceeding $40^{\circ} \mathrm{C}$. All freeze-drying were carried out by Hetosic CD 52 (Hetolab Equipments, Denmark) freeze dryer. The samples were pre-frozen in round bottom flasks in a methanol freezer (Hetofrig CB 5, Heto Birkero, Denmark) at $-30{ }^{\circ} \mathrm{C}$ to $-40{ }^{\circ} \mathrm{C}$. For TLC pre-coated $(0.2 \mathrm{~mm}$ thin coating of silica-gel on aluminum sheets) plate were used. For application of samples capillary tubes were used. TLC was done by the ascending technique in glass jars or tanks. The plates were examined under uv light at two different wave lengths $(254 \mathrm{~nm}$ and $350 \mathrm{~nm})$. Irrigated plates were developed by spraying with $1 \%$ vanillin in concentrated sulphuric acid followed by heating in an oven at $120{ }^{\circ} \mathrm{C}$ for 10 minutes. Glass column of different sizes varying from 
$(90 \mathrm{~cm} \times 10 \mathrm{~cm})$ large glass tubes fitted with a rota-flow to small $(30 \mathrm{~cm} \times 1 \mathrm{~cm})$ burette like tube fitted with teflon flow control unit were used. For stationary phase column grade silica gel (230-400 mesh, ASTM) was used. Highperformance liquid chromatography (HPLC) was carried out by a Shimadzu HPLC system using a Shim-pack $\mathrm{C}_{18}$ analytical column of serial No-0125, associated with two LC-10 AT VP pump and a UV detector (SPD-10 AVP, Shimadzu). For ultraviolet spectrum a Shimadzu UV-160 recording spectrophotometer was used. A shimadzu IR-470 spectrometer was used to obtain IR spectrum by making $\mathrm{KBr}$ pellets. The ${ }^{1} \mathrm{H},{ }^{13} \mathrm{C}$ and Dept-135 NMR spectra of different extracts, fractions and compounds were recorded by using a Bruker $400 \mathrm{MHz}$ machine. In all cases tetramethylsilane (TMS) was used as internal reference.

\section{Collection of Momordica charantia fruits}

Fresh fruits $(40 \mathrm{~kg})$ of Momordica charantia were bought from a local market of Dhaka city. The fruits were washed with water and the adhering water was removed by airdrying. Each of the fruit was divided into two halves with a sharp knife and the seeds were removed using a tea spoon. The seed free fresh fruit was sliced, dried in the air followed by drying in an oven at $40^{\circ} \mathrm{C}$.

\section{M. charantia fruit juice}

The dried fruit pulp was crushed in a kitchen blender (Philips) and the juice was squeezed out with pre-cleaned cloth filter. The residual pulp was further blended with an ultra-turrax adding some fresh juice to the pulp and more juice was squeezed with cloth filter. All the juice was centrifuged and the clear juice was immediately stored in a deep freezer $\left(-20^{\circ} \mathrm{C}\right)$.

\section{Liquid-liquid extraction (partition) of pure juice}

The centrifuged clear juice was partitioned with 1-butanol using a separating funnel $(1000 \mathrm{ml})$. Both 1-butanol part and aqueous part was separately collected and freeze-dried. Finally 1-butanol part, aqueous part, pure centrifuged freeze-dried juice were selected for biological testing and after biological study 1-butanol part was also selected for chemical analysis.

\section{Preparation of Sephadex LH-20 (reverse phase) column}

The required amount (200 $\mathrm{cm}^{3}$ column volume) of Sephadex LH-20 gel (particle size 25-100 $\mu \mathrm{m}$ ) was suspended in water for two hours containing 2, 2, 2trichloro-2, 2-dimethyl ethanol as a preservative. The gel was de-gassed for one hour with occasional shaking and the glass column was packed with the gel as a stationary phase. The column was conditioned with $\mathrm{H}_{2} \mathrm{O}(200 \mathrm{~mL}$ x3) following $\mathrm{CH}_{3} \mathrm{OH}(200 \mathrm{~mL} \times 3)$ and again with $\mathrm{H}_{2} \mathrm{O}(200$ $\mathrm{mL} \times 3$ ). Finally the column was equilibrated with $25 \%$ $\mathrm{MeOH}(200 \mathrm{~mL} \times 3)$ in water.

\section{Application of sample into the column}

The 1-butanol part $(8.0 \mathrm{~g})$ was suspended in $25 \% \mathrm{MeOH}$ and applied to the column. The sample was then eluted by $25 \% \mathrm{MeOH}$ in water $\left(200 \mathrm{~cm}^{3}\right)$ and the polarity of the solvent was gradually increased from $35,45,60,80$ to $100 \% \mathrm{MeOH}$ in water $\left(200 \mathrm{~cm}^{3}\right.$ each) followed by $100 \%$ acetone at the end. The eluted sample was collected in 63 test tubes $\left(25 \mathrm{~cm}^{3}\right.$ each). All the samples collected were monitored by TLC. The eluted samples were combined according to their $R_{f}$ values and three different fractions BP1 (2.45 g), BP2 (2.5 g) and BP3 (0.2 g) were obtained.

\section{Fractionation of BP3 by HPLC}

The gummy colored solid BP3 (150 mg) obtained from Sephadex LH-20 was further purified by preparative high performance liquid chromatography. Solvent system was chosen by passing the sample in an analytical $\mathrm{C}_{18}$ column. Separation of the sample was performed on a shim-pack RP-18 column using 50\% aqueous $\mathrm{CH}_{3} \mathrm{CN}$ (acetonitrile) as the mobile phase at a flow rate of $1.5 \mathrm{ml} / \mathrm{min}$ in a Shimadzu HPLC system. Three fractions were separated as F1 (4.6 $\mathrm{mg})$, F2 (1.6 mg) and F3 (5.0 mg).

\section{Purification of the fraction $F 1$}

The fraction F1 (4.6 mg) was washed with n-hexane and fatty materials was removed and dried. The dried solid material was resolubilised in methanol and kept for crystallization. But no crystal was found except solid material. The solid material was collected and labeled as MC1 (4.5 mg).

\section{Purification of the fraction F2}

The fraction F2 (1.6 mg) was washed with $\mathrm{n}$-hexane and fatty materials was removed and dried. The dried solid material was resolubilised in methanol and kept for crystallization. But no crystal was found except solid material. The solid material was collected and labeled as MC2 (1.5 mg).

\section{Results and Discussion}

\section{Characterization of the compound MCI}

The compound MC1 was obtained as amorphous solid with characteristics reddish colour. It was completely soluble in methanol. Melting point of the sample was recorded and found 112-115 ${ }^{\circ} \mathrm{C}$. It gave brown colour with vanillinsulphuric acid reagent indicating that $\mathrm{MC} 1$ might be a triterpenoid glycoside. The compound $\mathrm{MC} 1$ had an absorption maximum at $215 \mathrm{~nm}$ in $\mathrm{CH}_{3} \mathrm{OH}$.

The IR spectrum of MC1 had absorption band at $3400 \mathrm{~cm}^{-1}$ due to $-\mathrm{OH}$ stretching. Absorption bands at $1700 \mathrm{~cm}^{-1}$ and $1600 \mathrm{~cm}^{-1}$ due to $\mathrm{C}=\mathrm{O}$ and $\mathrm{C}=\mathrm{C}$ stretching vibration respectively. The band at $1075 \mathrm{~cm}^{-1}$ was due to the isopropyl group.

\section{${ }^{l} H$-NMR spectroscopy of the compound MCI}

The ${ }^{1} \mathrm{H}-\mathrm{NMR}$ spectrum of the compound MC1 had a broad singlet at $\delta=5.58$ that may be assigned to the olefinic proton (H-6) coupled with the methine proton of (H-7). The signal at $4.47(\mathrm{~J}=7.8 \mathrm{~Hz})$ which is a doublet indicate the anomeric proton as well as the $\beta$-linkage of the glucose to the aglycon. The signals at $3.83,3.77,3.65$ and 3.54 for 
different protons of the glucose moiety. The signal at 9.84 was due to the aldehydic proton.

The broad singlet at 3.14 was due to the methoxy group. The signals between 1.31-1.93 were due to methylene and methine protons. Seven singlets at 0.81, 0.90, 0.93, 0.96, $1.08,1.24$ and 1.28 were assigned for seven angular methyl groups present in the compound MC1.

${ }^{13}$ C-NMR and Dept-135 spectroscopy of the compound $M C 1$

The ${ }^{13} \mathrm{C}$ and Dept-135 NMR spectra of the compound MC1 had 37 signals indicating that the compound contained 37 carbons. By ${ }^{13} \mathrm{C}$-NMR spectrum and Dept-135 and their expansions and with the help of previously reported data all the methyl, methylene and methine carbons were distinguished (Table 1).

Comparing the ${ }^{13} \mathrm{C}-\mathrm{NMR}$ signals and the Dept-135 signals, the signals at 34.9, 29.7, 30.4, 30.3, 29.4, 28.6, 32.74, 27.3 and 30.1 were assigned nine methylene carbons at $\mathrm{C}-1, \mathrm{C}-2$, C-11, C-12, C-15, C-16, C-22, C-23 and C-24, respectively. The signals at 15.1, 19.4, 25.6, 18.9, 26.1, 25.7 and 17.8 ppm were due to methyl groups at C-18, C-21, C-26, C-27, C-28, C-29 and C-30, respectively. The signals at 76.7, $45.9,37.2,51.2$ and 37.1 were due to methine carbons at $\mathrm{C}$ 7, C-8, C-17 and C-20, respectively.

Table 1. Comparison between ${ }^{13} \mathrm{C}$-NMR data of compound $\mathrm{MC1}$ and previously reported data.

\begin{tabular}{|c|c|c|c|c|c|c|c|}
\hline 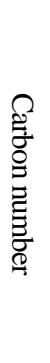 & 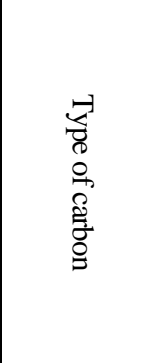 & 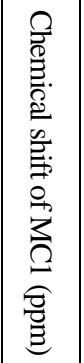 & 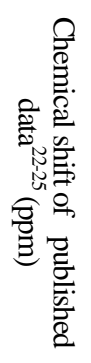 & 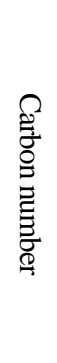 & 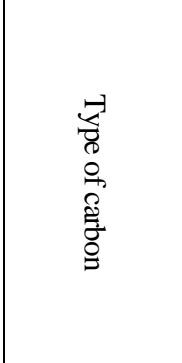 &  & 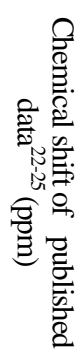 \\
\hline 1 & $-\mathrm{CH}_{2^{-}}$ & 34.9 & 34.8 & 21 & $-\mathrm{CH}_{3}$ & $\mid 19.4$ & 21.3 \\
\hline 2 & $-\mathrm{CH}_{2-}^{-}$ & 29.7 & 29.5 & 22 & $-\mathrm{CH}_{2-}$ & 32.74 & 36.2 \\
\hline 3 & $>\mathrm{CH}-\mathrm{OH}$ & 71.4 & 70.5 & 23 & $-\mathrm{CH}_{2-}^{-}$ & 27.3 & 27.7 \\
\hline 4 & $>C<$ & 42.5 & 41.5 & 24 & $-\mathrm{CH}_{2-}^{-}$ & 30.1 & 30.5 \\
\hline 5 & $>C<$ (olefinic) & $\mid 147.0$ & 145.6 & 25 & $>\mathrm{C}-\mathrm{O}-$ & 74.5 & 75.1 \\
\hline 6 & $>\mathrm{CH}$ (olefinic) & 123.0 & 124.0 & 26 & $-\mathrm{CH}_{3}$ & 25.6 & 25.5 \\
\hline 7 & $>\mathrm{CH}-\mathrm{O}$ & 76.7 & 76.0 & 27 & $-\mathrm{CH}_{3}$ & 18.9 & 18.8 \\
\hline 8 & $>\mathrm{CH}-$ & 45.9 & 45.1 & 28 & $-\mathrm{CH}_{3}$ & 26.1 & 27.5 \\
\hline 9 & $>\mathrm{C}<$ & 48.9 & 47.6 & 29 & $-\mathrm{CH}_{3}$ & 25.7 & 27.2 \\
\hline 10 & $>\mathrm{CH}-$ & 37.2 & 39.1 & 30 & $-\mathrm{CH}_{3}$ & 17.8 & 18.0 \\
\hline 11 & $-\mathrm{CH}_{2-}^{-}$ & 30.4 & 30.1 & $1^{\prime}$ & $>\mathrm{CH}$ (anomeric) & 101.8 & 101.8 \\
\hline 12 & $-\mathrm{CH}_{2-}^{-}$ & 30.3 & 30.0 & $2^{\prime}$ & $-\mathrm{CHOH}$ & 73.5 & 74.1 \\
\hline 13 & $>\mathrm{C}<$ & 50.3 & 50.1 & $3^{\prime}$ & $-\mathrm{CH}-\mathrm{OH}$ & 77.6 & 78.0 \\
\hline 14 & $>\mathrm{C}<$ & 50.8 & 50.2 & $4^{\prime}$ & $-\mathrm{CH}-\mathrm{OH}$ & 71.5 & 71.7 \\
\hline 15 & $-\mathrm{CH}_{2-}^{-}$ & 29.4 & 29.1 & $5^{\prime}$ & $-\mathrm{CH}-\mathrm{OH}$ & 77.7 & 78.1 \\
\hline 16 & $-\mathrm{CH}_{2-}^{-}$ & 28.6 & 28.5 & $6^{\prime}$ & $-\mathrm{CH}_{2^{-}}$ & 62.5 & 63.0 \\
\hline 17 & $>\mathrm{CH}_{-}$ & 51.2 & 55.6 & 37 & $-\mathrm{OCH}_{3}$ & 50.5 & 49.9 \\
\hline 18 & $-\mathrm{CH}_{3}$ & 15.1 & 15.1 & & & & \\
\hline 19 & $-\mathrm{CHO}$ & 209.9 & 207.7 & & & & \\
\hline 20 & $>\mathrm{CH}-$ & 37.1 & 36.7 & & & & \\
\hline
\end{tabular}

From the ${ }^{1} \mathrm{H}-\mathrm{NMR},{ }^{13} \mathrm{C}-\mathrm{NMR}$, Dept-135, IR and UV spectral data and also from chemical evidences the compound MC1 might be $3 \beta$, 7-O- $\beta$-glucopyranosyl-25methoxy cucurbita -5 -en-19-al (Fig. 1).

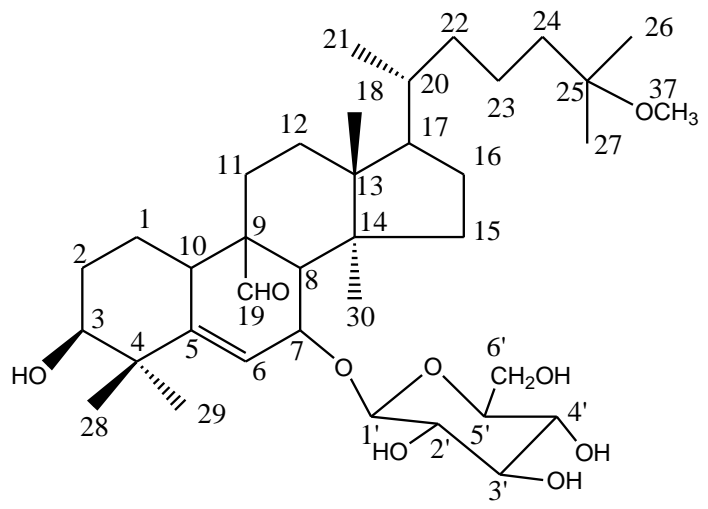

MC1



Fig. 1. Proposed structure of the compound $\mathrm{MC} 1$ and $\mathrm{MC} 2$

\section{Characterization of the compound MC2}

The compound MC2 was obtained as amorphous solid with characteristics reddish colour. The solid compound was completely soluble in methanol. Melting point of the sample was recorded and found $135-138^{\circ} \mathrm{C}$. It gave brown colour with vanillin-sulphuric acid reagent indicating that MC2 might be a triterpenoid glycoside. The compound $\mathrm{MC} 2 \mathrm{had}$ an absorption maximum at $215 \mathrm{~nm}$ in $\mathrm{CH}_{3} \mathrm{OH}$. The IR spectrum of MC2 had absorption band at $1620 \mathrm{~cm}^{-1}$ due to $\mathrm{C}=\mathrm{C}$ stretching vibration.

\section{${ }^{I} H$-NMR spectroscopy of the compound MC2}

The ${ }^{1} \mathrm{H}$-NMR spectrum of the compound MC2 had a broad singlet at $\delta=5.58$ that may be assigned to the olefinic proton (H-6) coupled with the proton of (H-7). The signal at $\delta=5.96$, which is a multiplet indicate another olefinic proton of $(\mathrm{H}-23)$. The sinals at $\delta=5.42$ (d) and 5.11 (d) were for the olefinic protons of $\mathrm{H}-7$ and $\mathrm{H}-24$, respectively.

The region from $\delta=3.50$ to 4.50 indicate the presence of glucose moiety as well as the $\beta$-linkage of the glucose to the aglycon. The broad singlets at 3.14 were due to the methoxy group. The signals between $1.34-1.93$ were due to methylene and methine protons. Seven singlets at 0.82 , $0.90,0.93,0.96,1.08,1.24$ and 1.29 were assigned for seven angular methyl groups present in the compound MC2. 


\section{${ }^{13} \mathrm{C}$-NMR and Dept-135-spectroscopy of the compound $M C 2$}

The ${ }^{13} \mathrm{C}-\mathrm{NMR}$ spectrum of the compound MC2 had 37 signals indicating that the compound contained 37 carbons. By ${ }^{13} \mathrm{C}-\mathrm{NMR}$-spectrum and Dept-135 and their expansions and with the help of previously reported compounds from fruits of Momordica charantia by Okabe et al. all the methyl, methylene, methine carbons were distinguished (Table 2).

Comparing the ${ }^{13} \mathrm{C}-\mathrm{NMR}$ signals and the Dept-135 signals, the signals at 33.6, 39.9, 47.9, 34.3, 28.3, 27.9, 64.1 and 28.8 were assigned eight methylene carbons at C-1, C-2, C11, C-12, C-15, C-16, C-19 and C-22 respectively. The signals at 13.9, 17.7, 24.7, 24.5 26.3, 25.0 and $17.3 \mathrm{ppm}$ were due to methyl groups at C-18, C-21, C-26, C-27, C28, C-29 and C-30 respectively. The signals at 55.2, 38.0, 49.1, 37.2 were due to methine carbons at C-8, C-10, C-17 and C-20, respectively. The signal at 49.9 is due to the methoxy proton.

From the ${ }^{1} \mathrm{H}-\mathrm{NMR},{ }^{13} \mathrm{C}-\mathrm{NMR}$, Dept-135, IR and UV spectral data and also from chemical evidences, the compound MC2 might be 5 $\beta$, 19-epoxy-3-Oglucopyranosyl-25-methoxy cucurbita-5, 23-dien (Fig. 1).

Table 2. Comparison between ${ }^{13} \mathrm{C}$ NMR data of compound MC2 and previously reported data.

\begin{tabular}{|c|c|c|c|c|c|c|c|}
\hline  & 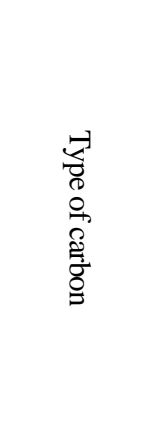 & 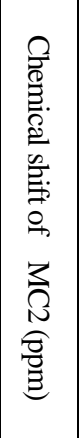 & 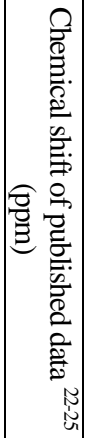 & 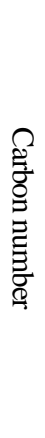 & 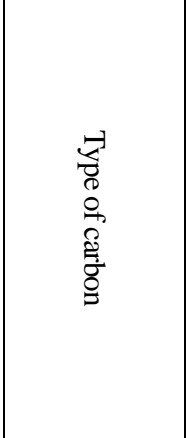 & 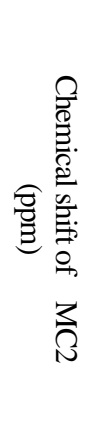 & 起 \\
\hline 1 & $-\mathrm{CH} 2-$ & 33.6 & 33.9 & 20 & $>\mathrm{CH}-$ & 37.1 & 36.7 \\
\hline 2 & $-\mathrm{CH} 2-$ & 39.9 & 39.5 & 21 & $-\mathrm{CH} 3$ & 17.7 & 17.3 \\
\hline 3 & $>\mathrm{CH}-\mathrm{O}-$ & 73.5 & 74.1 & 22 & $-\mathrm{CH} 2-$ & 28.8 & 29.2 \\
\hline 4 & $>\mathrm{C}<$ & 41.5 & 41.5 & 23 & $>\mathrm{CH}$ (olefinic) & 131.4 & 130 \\
\hline 5 & $>\mathrm{C}<$ & 87.5 & 87.9 & 24 & $>\mathrm{CH}$ (olefinic) & 139.4 & 139 \\
\hline 6 & $>\mathrm{CH}$ (olefinic) & 124.3 & 124.0 & 25 & $>\mathrm{C}-\mathrm{O}-$ & 74.5 & 75.1 \\
\hline 7 & $>\mathrm{CH}$ (olefinic) & 121.9 & 122.3 & 26 & $-\mathrm{CH} 3$ & 24.7 & 24.9 \\
\hline 8 & $>\mathrm{CH}-$ & 45.9 & 45.1 & 27 & $-\mathrm{CH} 3$ & 24.5 & 24.6 \\
\hline 9 & $>\mathrm{C}<$ & 47.5 & 47.6 & 28 & $-\mathrm{CH} 3$ & 26.3 & 26.5 \\
\hline 10 & $>\mathrm{CH}-$ & 38.2 & 39.1 & 29 & $-\mathrm{CH} 3$ & 25.0 & 25 . \\
\hline 11 & $-\mathrm{CH} 2-$ & 47.9 & 47.1 & 30 & $-\mathrm{CH} 3$ & 17.3 & 17. \\
\hline 12 & $-\mathrm{CH} 2-$ & 34.3 & 33.9 & $1^{\prime}$ & $>\mathrm{CH}$ (anomeric) & 101.0 & 101 \\
\hline 13 & $>\mathrm{C}<$ & 50.1 & 50.1 & $2^{\prime}$ & $-\mathrm{CHOH}$ & 72.4 & 72 . \\
\hline 14 & $>\mathrm{C}<$ & 50.2 & 50.2 & $3^{\prime}$ & $-\mathrm{CH}-\mathrm{OH}$ & 76.6 & 76. \\
\hline 15 & $-\mathrm{CH} 2-$ & 28.4 & 28.1 & $4^{\prime}$ & $-\mathrm{CH}-\mathrm{OH}$ & 68.9 & 69. \\
\hline 16 & $-\mathrm{CH} 2-$ & 27.9 & 28.1 & $5^{\prime}$ & -CH-OH & 76.5 & 76.1 \\
\hline 17 & $>\mathrm{CH}-$ & 55.2 & 55.6 & $6^{\prime}$ & $-\mathrm{CH} 2-$ & 61.8 & 62. \\
\hline 18 & $-\mathrm{CH} 3$ & 13.9 & 14.1 & 37 & $-\mathrm{OCH} 3$ & 49.9 & 49. \\
\hline 19 & $-\mathrm{CH} 2-$ & 64.1 & 64.9 & & & & \\
\hline
\end{tabular}

\section{References}

1. Walters, T.W., Decker-Walters, D.S., 1988. Balsam-pear (Momordica charantia, Cucurbitaceae). Econ. Bot., 42, 286288.

2. Shan, B., Xie, J.H., Zhu, J.H., Peng, Y., 2012. Ethanol modified supercritical carbon dioxide extraction of flavonoids from Momordica charantia L. and its antioxidant activity. Food Bioprod. Process., 90, 579-587.

3. Xu, X., Shan, B., Liao, C.H., Xie, J.H., Wen, P.W., Shi, J.Y., 2015. Anti-diabetic properties of Momordica charantia L. polysaccharide in alloxan-induced diabetic mice. Int. J. Biol. Macromol., 81, 538-543.

4. Zhang, F., Lin, L., Xie, J., 2016. A mini-review of chemical and biological properties of polysaccharides from Momordica charantia. Int. J. Biol. Macromol., 92, 246-253.

5. Cai, Y., Liu, M., Wu, X., Wang, Z., Liang, C., Yang, Y., 2010. Study on the antitumor and immune-stimulating activity of polysaccharide from Momordica charantia. Pharm. Clin. Res., 18, 131-134.

6. Zhang, P.P., Liu, J.F., Wang, C.L., Ye, Y.T., Xie, J.H., 2008. Study on the antimicrobial activities of the extracts fromMomordica charantia L. Nat. Prod. Res., 20, 721-724.

7. Puri, M., Kaur, I., Kanwar, R.K., Gupta, R.C., Chauhan, A., Kanwar, J.R., 2009. Ribosome inactivating proteins (RIPs) from Momordica charantia for anti viral therapy. Curr. Mol. Med., 9, 1080-1094.

8. Fang, E.F., Zhang, C.Z.Y., Wong, J.H., Shen, J.Y., Li, C.H., $\mathrm{Ng}, \mathrm{T} . \mathrm{B} ., 2$ 2012. The MAP30 protein from bitter gourd (Momordica charantia) seeds promotes apoptosis in liver cancer cells in vitro and in vivo. Cancer Lett., 324, 66-74.

9. Panda, B.C., Mondal, S., Devi, K.S.P., Maiti, T.K., Khatua, S., Acharya, K., Islam, S.S., 2015. Pecticpolysaccharide from the green fruits of Momordica charantia (Karela): Structural characterization and studyof immunoenhancing and antioxidant properties. Carbohydr. Res., 401, 24-31.

10. Pu, Z., Lu, B.Y., Liu, W.Y., Jin, S.W., 1996. Characterization of the enzymatic mechanism of momorcharin, a novel ribosome-inactivating protein with lower molecular weight of 11,500 purified from the seeds of bitter gourd (Momordica charantia). Biochem. Biophys. Res. Commun., 229, 287-294.

11. Meng, Y., Liu, S., Li, J., Meng, Y., Zhao, X., 2012. Preparation of an antitumor and antivirus agent: Chemical modification of $\alpha$-MMC and MAP30 from Momordica charantia L. with covalent conjugation of polyethyeleneglycol. Int. J. Nanomed., 7, 3133.

12. Fang, E.F., Zhang, C.Z.Y., Ng, T.B., Wong, J.H., Pan, W.L., Ye, X.J., Chan, Y.S., Fong, W.P., 2012. Momordica charantia lectin, a type II ribosome inactivating protein, exhibits antitumor activity toward human nasopharyngeal carcinoma cells in vitro and in vivo. Cancer Prev. Res., 5, 109-121.

13. Murakami, T., Emoto, A., Matsuda, H., Yoshikawa, M., 2001. Medicinal foods tuffs. XXI. Structures of new cucurbitane-type triterpene glycosides, goyaglycosides a, b, $\mathrm{c}, \mathrm{d}, \mathrm{e}, \mathrm{f}, \mathrm{g}$, and $\mathrm{h}$ and new oleanane-type triterpene saponins, goyasaponins I, II, and III, from the fresh fruit of Japanese Momordica charantia L. Chem. Pharm. Bull., 49, 54-63. 
14. Chen, J.C., Chiu, M.H., Nie, R.L., Cordell, G.A., Qiu, S.X., 2005. Cucurbitacins and cucurbitane glycosides: Structures and biological activities. Nat. Prod. Rep., 22, 386-399.

15. Harinantenaina, L., Tanaka, M., Takaoka, S., Oda, M., Mogami, O., Uchida, M., Asakawa, Y., 2006. Momordica charantia constituents and antidiabetic screening of the isolated major compounds. Chem. Pharm. Bull., 54, 10171021.

16. Zhang, L.J., Liaw, C.C., Hsiao, P.C., Huang, H.C., Lin, M.J., Lin, Z.H., Kuo, Y.H., 2014. Cucurbitane-type glycosidesfrom the fruits of Momordica charantia and their hypoglycaemic and cytotoxic activities. J. Funct. Foods., 6, 564-574.

17. Zhang, L.J., Huang, H.T., Liaw, C.C., Huang, S.Y., Lin, Z.H., Kuo, Y.H., 2016. Cucurbitane-type triterpenes and glycoside from the rattan of wild Momordica charantia and their anti-inflammatory and cytotoxic activities. Planta Med., 81, S1-S381.

18. Kubola, J. and Siriamornpun, S., 2008. Phenolic contents and antioxidant activities of bitter gourd (Momordica charantia L.) leaf, stem and fruit fraction extracts in vitro. Food Chem., 110, 881-890.

19. Chuang, C.Y., Hsu, C., Chao, C.Y., Wein, Y.S., Kuo, Y.H., Huang, C.J., 2006. Fractionation and identification of 9c, 11t, 13t-conjugated linolenic acid as an activator of PPAR in bitter gourd (Momordica charantia L.). J. Biomed. Sci., 13, 763-772.
20. Shan, B., Xie, J.H., Zhu, J.H., Peng, Y., 2012. Ethanol modified supercritical carbon dioxide extraction of flavonoids from Momordica charantia L. and its antioxidant activity. Food Bioprod. Process., 90, 579-587.

21. Tan, S.P., Stathopoulos, C., Parks, S., Roach, P., 2014. An optimised aqueous extract of phenolic compounds from bitter melon with high antioxidant capacity. Antiox., 3, 814-829.

22. Yasuda, M., Iwamoto, M., Okabe, H. and Yamauchi, T., 1984. Structures of Momordicines I, II and III, the bitter principles in the leaves and vines of Momordica charantia L. Chem. Pharm. Bull., 32, 2044-2047.

23. Okabe, H., Miyahara, Y., Yamauchi, T., Miyahara, K., Kawasaki, T., 1980. Studies on the constituents of Momordica charantia L. I. Isolation and characterization of Momordicosides A and B, glycosides of a pentahydroxycucurbitane triterpine. Chem. Pharm. Bull., 28, 2753-2762.

24. Miyahara, Y., Okabe, H., Yamauchi, T., 1981. Studies on the constituents of Momordica charantia L. II. Isolation and Characterization of minor seed glycosides, Momordicosides C, D and E. Chem. Pharm. Bull., 29, 1567-1579.

25. Okabe, H., Miyahara, Y., Yamauchi, T., 1982. Studies on the constituents of Momordica charantia L. III Characterization of new cucurbitacin glycosides of the immature fruits (1). Structures of Momordicoside G, $\mathrm{F}_{1}, \mathrm{~F}_{2}$ and I. Chem. Pharm. Bull., 30, 3977-3982. 
